\title{
NOTES
}

\section{Anionic Polymerization of 2,3,4,5,6-Pentafluorostyrene}

\author{
Shin Nishimura, ${ }^{\dagger}$ Akira NAGAI, Akio TAKAHASHI, \\ Tadashi NARITA, ${ }^{*}$ Tokio HagIWARA, ${ }^{*}$ \\ and Hiroshi HAMANA* \\ Hitachi Research Laboratory, Hitachi Ltd., \\ Kuji-cho, Hitachi, Ibaraki 319-12, Japan \\ * Department of Environmental Engineering, Saitama Institute of \\ Technology, Okabe-machi, Osato-gun, \\ Saitama 369-02, Japan
}

(Received March 27, 1989)

KEY WORDS Anionic Polymerization / 2,3,4,5,6-Pentafluorostyrene
MNDO Method /

A series of ionic polymerization studies of several fluorine-containing vinyl monomers have previously been reported. ${ }^{1-7}$ The high electron-withdrawing effect of fluoroalkyl substituents reduces electron density of the vinyl groups so that reactivity towards carbanions is increased. It has been pointed out that the $e$ values of fluoroalkyl acrylates and methacrylates are so large that these monomers can easily undergo anionic polymerization with initiators of relatively low nucleophilicity. The same effect has been observed on the anionic polymerization of $o$ - and $p$-trifluoromethylstyrenes. $^{8}$

However, only a few reports on the anionic polymerization of fluorinated styrenes are available. ${ }^{9}$ The reactivity of fluorinated styrenes such as 2,3,4,5,6-pentafluorostyrene (PFS) might be strongly influenced by the pentafluorophenyl moiety. Pryor and Huang ${ }^{10}$ have shown the $Q$ and $e$ values of PFS to be 0.69 and 0.74 , respectively, by radical copolymerization of PFS with styrene. PFS has such a large positive $e$ value that the monomer is expected to be easily polymerized with anionic

\footnotetext{
† To whom all correspondence should be addressed.
}

initiators.

The present paper deals with some examinations of anionic polymerization reactivity of PFS by various methods such as anionic polymerization initiated with several compounds, anionic copolymerization with styrene, and the calculation of charge distribution of PFS and propagating carbanionic end group by MNDO method.

\section{EXPERIMENTAL}

Most of the experiments related to polymerization reactions were carried out under purified nitrogen atmosphere to exclude oxygen and atmospheric moisture.

\section{Reagents}

Commercial 2,3,4,5,6-pentafluorostyrene (PFS) was purified by refluxing over $\mathrm{CaH}_{2}$, followed by distillation under reduced pressure (bp $62^{\circ} \mathrm{C} / 50 \mathrm{mmHg}$ ). Styrene was purified by the usual method. Toluene and tetrahydrofuran (THF) were refluxed over $\mathrm{CaH}_{2}$ and then distilled under nitrogen. 1,2-Dimethoxy- 
ethane (DME) was purified by the same method and further purification was carried out by refluxing with $\mathrm{Al}\left(\mathrm{C}_{2} \mathrm{H}_{5}\right)_{3}$ and distillation under nitrogen. Commercial $n-\mathrm{C}_{4} \mathrm{H}_{9} \mathrm{Li}$ and $\mathrm{C}_{2} \mathrm{H}_{5} \mathrm{MgBr}$ were used as initiators after determination of the concentrations of the active species by alkalimetry. $t-\mathrm{C}_{4} \mathrm{H}_{9} \mathrm{OLi}$ was purified by sublimation in vacuo. $\mathrm{LiAlC}_{4} \mathrm{H}_{9}\left(\mathrm{C}_{2} \mathrm{H}_{5}\right)_{3}$ and (iso- $\left.\mathrm{C}_{3} \mathrm{H}_{7}\right)_{2} \mathrm{NLi}$ were synthesized by reactions of $\mathrm{Al}\left(\mathrm{C}_{2} \mathrm{H}_{5}\right)_{3}$ and (iso- $\left.\mathrm{C}_{3} \mathrm{H}_{7}\right)_{2} \mathrm{NH}$ with $n-\mathrm{C}_{4} \mathrm{H}_{9} \mathrm{Li}$, respectively, under nitrogen. $\left(\mathrm{C}_{2} \mathrm{H}_{5}\right)_{2}$ Alacac was synthesized from equimolar reaction of $\mathrm{Al}\left(\mathrm{C}_{2} \mathrm{H}_{5}\right)_{3}$ and acetylacetone. Commercial $\mathrm{Al}\left(\mathrm{C}_{2} \mathrm{H}_{5}\right)_{3}, \mathrm{Zn}\left(\mathrm{C}_{2} \mathrm{H}_{5}\right)_{2}$, and (iso- $\left.\mathrm{C}_{3} \mathrm{H}_{7}\right) \mathrm{NH}$ were distilled under reduced pressure.

\section{Procedures}

A glass ampoule was charged with monomer $(21.7 \mathrm{mmol})$, initiator $(0.43 \mathrm{mmol})$ and solvent using a syringe under nitrogen (total volume: $20 \mathrm{ml}$ ). The ampoule was sealed and kept at a constant temperature and the reaction mixture was magnetically stirred. The polymer was isolated by reprecipitation with methanol and dried to a constant weight.

Composition of styrene-PFS copolymer was estimated from elemental analysis. Gel permeation chromatogram (GPC) was measured with a Hitachi L-6000 chromatograph equipped with a Gelpack R-400 M column using THF as an eluent. Charge distribution of monomer was calculated by the MNDO method. ${ }^{11}$

\section{RESULTS AND DISCUSSION}

The results of the polymerization of PFS with several anionic initiators are summarized in Table I. Based on the relationship between the reactivity of the vinyl monomers and that of anionic initiators proposed by Tsuruta, ${ }^{12}$ monomers with high $e$ values should produce polymers with anionic initiators of relatively low nucleophilicity. As shown in Table I, PFS can be polymerized with even pyridine which belongs to the group of the lowest nucleo-
Table I. Conditions and results of the polymerization of PFS at room temperature $\left(\mathrm{ca} .25^{\circ} \mathrm{C}\right)$

\begin{tabular}{|c|c|c|c|}
\hline \multirow{2}{*}{ Initiator } & \multirow{2}{*}{ Solvent } & \multirow{2}{*}{$\frac{\text { Time }}{\text { day }}$} & \multirow{2}{*}{$\frac{\text { Yield }}{\%}$} \\
\hline & & & \\
\hline \multirow[t]{3}{*}{$n-\mathrm{C}_{4} \mathrm{H}_{9} \mathrm{Li}$} & THF & 7 & 16.6 \\
\hline & Toluene & 7 & 1.8 \\
\hline & DME & 7 & 7.7 \\
\hline $\mathrm{C}_{2} \mathrm{H}_{5} \mathrm{MgBr}$ & THF & 7 & 4.8 \\
\hline $\mathrm{LiAlC}_{4} \mathrm{H}_{9}\left(\mathrm{C}_{2} \mathrm{H}_{5}\right)_{3}$ & THF & 7 & 3.6 \\
\hline$t-\mathrm{C}_{4} \mathrm{H}_{9} \mathrm{OLi}$ & THF & 7 & 2.9 \\
\hline$\left(\text { iso- } \mathrm{C}_{3} \mathrm{H}_{7}\right)_{2} \mathrm{NLi}$ & THF & 7 & 0 \\
\hline$\left(\mathrm{C}_{2} \mathrm{H}_{5}\right)_{2}$ Alacac & THF & 7 & 2.5 \\
\hline \multirow[t]{2}{*}{$\left(\mathrm{C}_{2} \mathrm{H}_{5}\right)_{2} \mathrm{Zn}$} & THF & 16 & 6.6 \\
\hline & Toluene & 16 & 0 \\
\hline Pyridine & THF & 7 & 2.0 \\
\hline
\end{tabular}

Table II. Polymerization of PFS with $n-\mathrm{C}_{4} \mathrm{H}_{9} \mathrm{Li}$ as a function of time at room temperature. ${ }^{a}$

\begin{tabular}{|c|c|c|c|}
\hline Temp & Time & Yield & \\
\hline${ }^{\circ} \mathrm{C}$ & day & $\%$ & \\
\hline \multirow[t]{3}{*}{ Room temp. $^{b}$} & 1 & 2.9 & 1.0 \\
\hline & 7 & 16.6 & 5.2 \\
\hline & 17 & 25.0 & 5.7 \\
\hline \multirow[t]{3}{*}{60} & 1 & 11.0 & 0.9 \\
\hline & 7 & 43.5 & 3.7 \\
\hline & 17 & 42.0 & - \\
\hline
\end{tabular}

a In THF.

b ca. $25^{\circ} \mathrm{C}$.

philicity $^{12}$ though the polymer yield is low. Other initiators such as $\mathrm{LiAlC}_{4} \mathrm{H}_{9}\left(\mathrm{C}_{2} \mathrm{H}_{5}\right)_{3}$, $\left(\mathrm{C}_{2} \mathrm{H}_{5}\right)_{2}$ Alacac, and $\mathrm{Zn}\left(\mathrm{C}_{2} \mathrm{H}_{5}\right)_{2}$ can also produce polymers. PFS is found to show high reactivity towards anionic initiators. The highest yield is obtained with $n-\mathrm{C}_{4} \mathrm{H}_{9} \mathrm{Li}$, and THF is preferable with regard to polymerization solvents. The products obtaineld here showed similar GPC curves. The molecular weight distribution was unimodal.

The anionic polymerization of PFS initiated with $n-\mathrm{C}_{4} \mathrm{H}_{9} \mathrm{Li}$ was investigated with variation of temperature and polymerization time. The yields of poly(PFS) increased with reaction temperature. At $60^{\circ} \mathrm{C}$, it increased up to $43.5 \%$. Higher temperature seems to be preferable for 
the polymerization of PFS.

Table II shows the relationship between reaction time and yields of poly(PFS) at room temperature $\left(c a .25^{\circ} \mathrm{C}\right)$ and $60^{\circ} \mathrm{C}$. The yields increase continuously for 7 days. Molecular weights also increase with reaction time.

The copolymerization of PFS with styrene initiated by $n-\mathrm{C}_{4} \mathrm{H}_{9} \mathrm{Li}$ showed a similar copolymerization curve as that initiated by AIBN. ${ }^{10}$ The monomer reactivity ratios $r_{1}(\mathrm{St})$ and $r_{2}$ (PFS) calculated by the FinemannRoss method are 0.33 and 0.43 , respectively. In the case of radical copolymerization, they are 0.43 and 0.22 , respectively. The product $r_{1} r_{2}$ is less than unity which indicates a crosspropagating tendency of copolymerization.

As shown in Table I, initiators examined here are found to yield some polymeric products. In contrast styrene is polymerized only with the initiators of the highest reactivity such
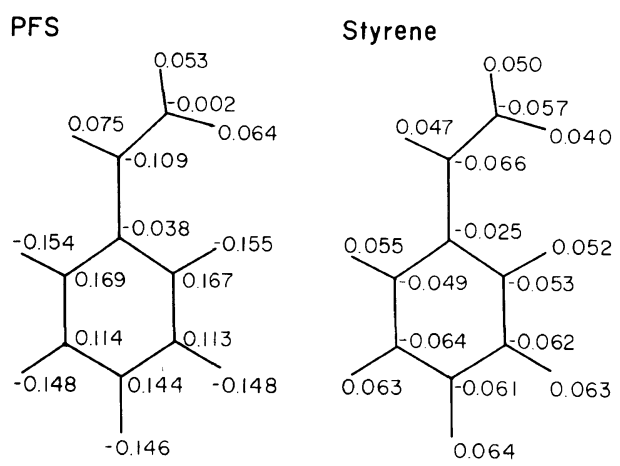

Figure 1. Atomic charge distribution of PFS and styrene calculated by means of MNDO method.
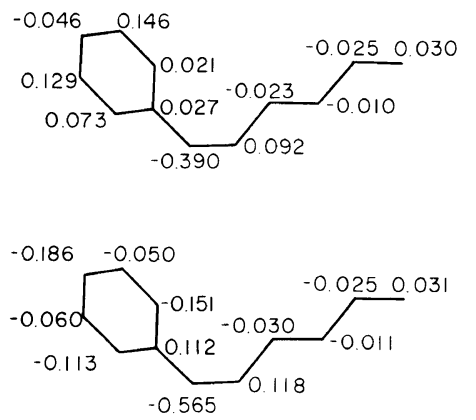

Styrene

Figure 2. Atomic charge distribution of skeletal carbon atoms of PFS and styrene added to $n$-butyl anion. as $n-\mathrm{C}_{4} \mathrm{H}_{9} \mathrm{Li},{ }^{12}$ and the polymerization reaction is completed within a few hours once the initiation reaction takes place. ${ }^{13}$ To determine the reason for the difference between the reactivity of PFS and styrene, the calculations of the atomic charge of PFS and styrene were carried out by the MNDO method. The results are shown in Figure 1. The atomic charges of the $\beta$-carbons of styrene and PFS are -0.057 and -0.002 , respectively. PFS can, therefore, react more readily with the carbanions of lower nucleophilicity because of the lower charge density of the $\beta$-carbon.

The atomic charge calculation of the active species in anionic polymerization was also tried by the same method. The active species were regarded as 1-perfluorophenyl- $n$-hexyl and 1-phenyl- $n$-hexyl anions which are the adducts of the monomers and $n$-butyl anion. The results are shown in Figure 2. Atomic charges of the carbanions of the adducts of PFS and styrene are -0.390 and -0.565 , respectively. The atomic charge of the carbanion on PFS-adduct is found to be more dispersed due to the electron-withdrawing effect of the fluorine atoms. The lower polymerization reactivity of PFS might, therefore, be controlled by the lower electron-density of propagating PFS anion end group.

In conclusion, the anionic polymerization reactivity of PFS is found to be higher than that of styrene since the polymerization of PFS takes place even with initiators of lower reactivity such as ate complexes, organoaluminum, organozinc and pyridine though apparent yields of polymers are relatively low. The anionic copolymerization of PFS with styrene seems to be largely controlled by the reactivities of both monomers and polymer anions as the cross-propagations are tend to take place. The reactivities of these monomers derived from polymer yields are supported by the atomic charge calculations of these monomers and the model compounds of the propagating polymer anion end groups. 


\section{REFERENCES}

1. T. Narita, T. Hagiwara, and H. Hamana, Makromol. Chem., Rapid Commun., 6, 5 (1985).

2. T. Narita, T. Hagiwara, and H. Hamana, Makromol. Chem., Rapid Commun., 6, 175 (1985).

3. T. Narita, T. Hagiwara, and H. Hamana, M. Goto, Makromol. Chem., 187, 731 (1986).

4. T. Narita, T. Hagiwara, H. Hamana, H. Yanagisawa, and Y. Akazawa, Makromol. Chem., 187, 739 (1986).

5. T. Narita, T. Hagiwara, H. Hamana, T. Miyasaka, A. Wakayama, and T. Hotta, Makromol. Chem., 188, 273 (1987).

6. T. Narita, T. Hagiwara, H. Hamana, and T. Nara,
Polym. J., 20, 277 (1988).

7. T. Narita, T. Hagiwara, H. Hamana, and S. Maesaka, Polym. J., 20, 519 (1988).

8. T. Narita, T. Hagiwara, H. Hamana, T. Irie, and H. Sugiyama, Polym. J., 19, 985 (1987).

9. A. A. Wall, Fluoropolymers, Wiley-Interscience, New York, N.Y., 1972.

10. W. A. Pryor and T. L. Huang, Macromolecules, 2, 70 (1969).

11. M. J. S. Dewar and W. Thiel, J. Am. Chem. Soc., 99, 4899 (1977).

12. T. Tsuruta, "Progress in Polymer Science, Japan," Vol. 3, Kodansha, Tokyo, 1972, p 1.

13. F. J. Welch, J. Am. Chem. Soc., 81, 1345 (1959). 